\title{
Effect of parathyroid hormone on hypogonadism induced bone loss of proximal femur of orchiectomized rat
}

\author{
M. Tezval · G. Serferaz $\cdot$ T. Rack $\cdot$ L. Kolios $\cdot$ \\ S. Sehmisch $\cdot$ U. Schmelz $\cdot$ H. Tezval $\cdot$ \\ K. M. Stuermer • E. K. Stuermer
}

Received: 7 September 2010 / Accepted: 18 January 2011 / Published online: 5 February 2011

(C) The Author(s) 2011. This article is published with open access at Springerlink.com

\begin{abstract}
Purpose Management of hypogonadism-induced osteoporosis in elderly men is still a challenge. We investigated the short-term effects of parathyroid hormone (PTH) treatments on strength, micro-architecture, and mineral density of trochanteric region of orchiectomized rat femur.

Methods Eight-month-old male Sprague-Dawley rats ( $n=44)$ were divided into two groups: (1) orchiectomized (ORX) and (2) sham group. Twelve weeks after orchiectomy, half of the orchiectomized animals were treated with daily subcutaneously injected PTH $(0.040 \mathrm{mg} / \mathrm{kg} / \mathrm{BW})$ (ORX-PTH) for 5 weeks. The other half remained untreated (ORX). The sham-operated group was divided and treated in the same way (sham, sham-PTH). After 5 weeks, both femurs were excised for biomechanical and histomorphometric analysis, trabecular measurements, mineral content assessment, and immunofluorescence analysis.

Results The femoral trochanteric strength after PTH treatment was enhanced in the breaking test $\left(\mathrm{ORX}-\mathrm{F}_{\max }=\right.$ 158.7 N vs. ORX + PTH-F max $=202 \mathrm{~N}$ ). Stiffness of treated

M. Tezval $(\bowtie) \cdot$ G. Serferaz $\cdot$ T. Rack $\cdot$ L. Kolios $\cdot$ S. Sehmisch

K. M. Stuermer · E. K. Stuermer

Department of Trauma and Reconstructive Surgery,

Georg-August-University of Goettingen,

Robert Koch Street 40, 37075 Goettingen, Germany

e-mail: mtezval@med.uni-goettingen.de

U. Schmelz

Medical Institute of General Hygiene and Environmental Health,

University of Goettingen, Goettingen, Germany

H. Tezval

Department of Urology and Urological Oncology,

Hannover Medical School, Hannover, Germany
\end{abstract}

ORX animals reached nearly the levels observed in untreated sham rats. PTH therapy improved the trabecular connectivity, width, and area (ORX-Tb.Ar $=47.79 \%$ vs. ORX + PTH-Tb.Ar $=68.47 \%, P<0.05)$ in the proximal femur. The treated rats showed significantly improved mineral content in ashed femurs (ORX-mineral content $=$ $43.73 \%$ vs. ORX + PTH-mineral content $=49.49 \%$ ) when compared to the untreated animals. A comparison of widths of fluorescence bands in cortical bone of the subtrochanteric cross-sections showed a significant increase in oppositions after the PTH therapy.

Conclusions Our finding supports the hypothesis that PTH therapy seems to be a rational therapy in patients with hypogonadism induced bone loss and improves the bone strength of trochanteric region of rat femur.

Keywords Hypogonadism · Osteoporosis · Parathyroid hormone $\cdot$ Trochanteric region

\section{Introduction}

One of the most important causes of osteoporosis in men seems to be the change in level of sex steroid hormone in older ages [1]. The testosterone deficiency induced osteoporosis in men develops later in life than in women but the morbidity and mortality after osteoporotic fractures are greater [1-3]. In addition to the primary hormone deficiency in old men, the pharmacologic or surgical androgen ablation treatment (AA) of prostate cancer increases the risk of osteoporosis and fractures [4]. For these patients, the British Columbia Cancer Agency recommended Guidelines to arrange for bone mineral density (BMD) and begin of osteoporosis prophylaxis if AA was to be used for 6 month or longer [4]. 
The recommended therapy modalities include both pharmacologic and nonpharmacologic interventions $[5,6]$. In testosterone deficient old men, the hormone replacement therapy is discussed controversially and in patients with prostate cancers after AA treatment even contraindicated [7].

The positive anabolic effect of parathyroid hormone (PTH) on postmenopausal osteoporotic bone in women led researchers in the last years to mention this hormone also for treatment of osteoporosis in men [8,9]. The key role here plays the intermittent and not the continuous application of the hormone $[10,11]$.

Rodents, like rat as animal model, have been established for investigations in osteoporosis researches, especially because the animals develop severe osteoporosis within few weeks after gonadectomy [12].

In osteoporotic women and men, the femoral trochanteric fracture is one the most common fracture type. The proximal part of femur in both rat and human contains a grate content of trabecular and cortical bone with an intact periosteal shell. For these reasons, this skeletal site has gained a special meaning and a great importance in osteoporosis studies [10].

In the present work, we investigated the antiosteoporotic potential of intermittent application of PTH on trochanteric region of orchiectomized male rat.

\section{Materials and methods}

Experimental animals and substances

The experiments were carried out using 44 eight-month-old male Sprague-Dawley rats. The animals were initially randomized by weight (no significant weight differences between the groups) and divided into two groups: (1) orchiectomized (ORX) and (2) sham groups (22 rats in each group). Twelve weeks after orchiectomy, eleven of the orchiectomized animals were treated with daily (7 days a week) subcutaneously injected PTH (1-34) $(0.04 \mathrm{mg} / \mathrm{kg}$ body weight, one injection daily) (ORX-PTH) for 5 weeks. The other half (11 rats) remained untreated (ORX). The sham-operated group was divided and treated in the same way (sham, sham-PTH with also 11 rats in each groups).

After 5 weeks, both femurs were excised for biomechanical and histomorphometric analysis, trabecular measurements, mineral content assessment, and immunofluorescence analysis. The operations were performed under intraperitoneal ketamine (Medistar, Holzwickede, Germany) and xylazine (Riemser, Greifswald-Insel Riems, Germany) anesthesia (40 and $10 \mathrm{mg} / \mathrm{kg}$ body weight, respectively).

The experimental procedures were approved by the local ethics commission under German animal protection law (permission from 12/05/03, Az: 509.42502/01-53.03 Bezirkregierung Braunschweig). Twelve weeks after bilateral ORX, the bilateral osteotomy and osteosynthesis (plate) of tibia were performed. We started the drug treatments after osteosynthesis, which continued for the next 5 weeks. After 5 weeks of drug therapy, the rats were euthanized and both femurs were dissected free of soft tissue to be used for biomechanical and histomorphometric tests. The results of tibia osteotomy have recently been submitted.

During the treatment, the animals were subcutaneously injected with four fluorescent substances (Merck, Darmstadt, Germany) to mark the process of bone formation, especially in the cortical surface. The following fluorescent agents injected were xylenol orange $(90 \mathrm{mg} / \mathrm{kg})$ on day 13 , calcein green $(10 \mathrm{mg} / \mathrm{kg})$ on day 18 , alizarin red $(30 \mathrm{mg} / \mathrm{kg})$ on day $24 / 26$, and tetracycline $(25 \mathrm{mg} / \mathrm{kg})$ on day 35 . The results of the fluorochrome labeling were analyzed in crosssections of femurs $15 \mathrm{~mm}$ distal from the femoral head in the subtrochanteric region.

\section{Biomechanical test}

The biomechanical test was performed with our new breaking test as previously described [10]. Force was applied with a ZWICK-testing machine, type 145660 Z020/TND (Zwick/Roell, Ulm, Germany), from the lateral side of the bone (vertically to the femoral length axis) to the greater trochanter using a metallic stamp.

The range of assessment was from $2 \mathrm{~N}$ to $500 \mathrm{~N}$. The force was applied until the femur was broken in the trochanteric region. Displacement and load were recorded, and ultimate breaking strength (maximal load, $\mathrm{F}_{\max }(\mathrm{N})$ ) and stiffness (slope of the linear part of the curve, representing elastic deformation, $\mathrm{N} / \mathrm{mm}$ ) have been calculated.

The testXpert software continuously recorded the force applied until the femur was broken.

Radiographs in the anterior-posterior and lateral view were performed for all left femurs tested in the study.

\section{Cancellous and cortical bone histomorphometry}

Sagittal sections (embedded in methylmethacrylate, $150 \mu \mathrm{m}$ thick) of the proximal femur were prepared using a microtome (Leica, Sawmicrotom 1600). The region of interest for the histomorphometric test was a frame between the epiphyseal line and the femoral neck ( $2 \mathrm{~mm}$ distally). The microradiographs of the sagittal sections of proximal femurs were used to analyze the structural changes in the trabecular surfaces.

A digitizing morphometric system was used to measure bone histomorphometric parameters. The system consisted of a microscope (Leica-System MZ 7.5), a digitizing pad coupled to a PC and a morphometry program (Qwin software). 
Table 1 Results of the body weights, biomechanical test, histomorphometric analysis, and bone mineral contents

\begin{tabular}{|c|c|c|c|c|c|c|c|c|}
\hline & \multicolumn{2}{|l|}{ Sham } & \multicolumn{2}{|l|}{ ORX } & \multicolumn{2}{|c|}{ ORX + PTH 7x/w } & \multicolumn{2}{|c|}{ Sham + PTH 7x/w } \\
\hline & Mean & STD & Mean & STD & Mean & STD & Mean & STD \\
\hline \multicolumn{9}{|l|}{ Body weight } \\
\hline Before ORX (g) & 650.9 & 74.89 & 613.6 & 54.83 & 662.7 & 79.92 & 631.9 & 55.30 \\
\hline At the end of trial $(\mathrm{g})$ & $726.5^{\mathrm{a}}$ & 82.10 & 630.4 & 57.82 & 677.5 & 95.35 & 691.2 & 71.72 \\
\hline Weight gain $(\mathrm{g})$ & $75.6^{\mathrm{a}}$ & & 16.8 & & 14.8 & & $59.3^{\mathrm{a}}$ & \\
\hline \multicolumn{9}{|l|}{ Biomechanical changes } \\
\hline Maximal load $\left(\mathrm{F}_{\max }\right)(\mathrm{N})$ & $212.8^{\mathrm{a}}$ & 43.21 & 158.7 & 16.09 & 202.0 & 21.74 & $226.2^{\mathrm{a}}$ & 51.70 \\
\hline Stiffness $(\mathrm{N} / \mathrm{mm})$ & $325.1^{\mathrm{a}}$ & 101.1 & 215.1 & 44.13 & $320.9^{\mathrm{a}}$ & 72.90 & $322.6^{\mathrm{a}}$ & 81.51 \\
\hline \multicolumn{9}{|l|}{ Histomorphometry } \\
\hline Connectivity (N.Nd/mm²) & $11.90^{\mathrm{a}}$ & 1.76 & 9.17 & 1.81 & 10.24 & 1.73 & $11.56^{\mathrm{a}}$ & 1.91 \\
\hline Trabecular area (Tb.Ar) (\%) & $63.39^{\mathrm{a}}$ & 7.69 & 47.79 & 4.13 & $68.47^{\mathrm{a}}$ & 8.22 & $71.81^{\mathrm{a}}$ & 6.48 \\
\hline Trabecular width $(\mathrm{mcm})$ & 12.80 & 1.24 & 11.23 & 0.96 & $14.93^{\mathrm{a}}$ & 2.61 & $14.70^{\mathrm{a}}$ & 1.67 \\
\hline Trabecular nodes (N.Nd) & $58.40^{\mathrm{a}}$ & 12.49 & 39.58 & 9.13 & 49.00 & 11.66 & $52.25^{\mathrm{a}}$ & 5.95 \\
\hline Ratio B.Dm/M.Dm & $1.78^{\mathrm{a}}$ & 0.09 & 1.64 & 0.1 & $1.95^{\mathrm{a}}$ & 0.1 & $2.04^{\mathrm{a}}$ & 0.11 \\
\hline Mineral content (after ashing) in left femurs (\%) & 44.45 & 1.21 & 43.73 & 1.90 & $49.49^{\mathrm{a}}$ & 6.14 & $48.13^{\mathrm{a}}$ & 0.88 \\
\hline
\end{tabular}

The $P$-value of the difference between treated and untreated animals was calculated using a one-way ANOVA. $P$-values $<0.05$ were considered significant

ORX orchiectomy, B.Dm bone diameter, Ma.Dm marrow diameter

${ }^{\text {a }} P<0.05$ vs. ORX

We assessed trabecular area (Tb.Ar), the number of trabecular nodes (N.Nd), trabecular connectivity $\left(\mathrm{N} . \mathrm{Nd} / \mathrm{mm}^{2}\right)$, and mean trabecular width (Tb.Wi) [13].

In our study, we measured the ratio between bone diameter (B.Dm) and marrow diameter (Ma.Dm) in the cross-sections $15 \mathrm{~mm}$ distal of the femoral head in the subtrochanteric area. We assessed the B.Dm of the crosssections in the midline of the sections (ventro-dorsal axis) and on the same line as the Ma.Dm as previously described. The B.Dm/Ma.Dm ratio was used to compare changes in the cortical width of the subtrochanteric region of the rat femur among all groups.

\section{Ashing}

To determine the amount of mineralized bone, the right femurs were mineralized at $750^{\circ} \mathrm{C}$ and weighed to the nearest $10^{-5} \mathrm{~g}$. The femurs were weighed before and after ashing. At the end of the experiment, the mineral content of each bone was indicated as a percentage of the total weight of the same femur (weight after ashing/weight before ashing).

\section{Statistics}

The mean values of the differences between the study groups in all of the comparative bioassays were assessed using oneway ANOVA tests (Prism TM 4.0, Graph Pad, San Diego, USA). $P$-values $<0.05$ were considered significant.

\section{Results}

Changes in the body weight and mineral content

At the beginning of the study, no significant weight differences between all rats could be observed. At the end of the trial, we could observe a clear increase in body weight in both sham groups (sham: $75.6 \mathrm{~g}$ weight gain and sham + PTH 7x/w: $59.3 \mathrm{~g}$ weight gain). At the end of the study, the increase in the body weight led to significant differences between the both sham groups and the ORX animals $(\mathrm{ORX}=16.8 \mathrm{~g}$ weight gain, ORX $+\mathrm{PTH} 7 \mathrm{x} / \mathrm{w}=$ $14.8 \mathrm{~g}$ weight gain) (Table 1).

The measured mineral content of left femurs showed significant higher results after PTH substitution in both ORX + PTH 7x/w (49.49\%) and sham + PTH 7x/w (48.13\%) compared to the ORX rats $(43.73 \%)$.

Results of the histomorphometry test

After PTH therapy, there was a slightly increase concerning trabecular connectivity $\left(\mathrm{N} . \mathrm{Nd} / \mathrm{mm}^{2}\right)$ in the ORX + PTH 7x/ w animals (10.24) in comparison with the ORX rats (9.17). The result, however, was not statistically significant. The rate of Tb.Ar and Tb.Wi was in both PTH-treated groups (ORX + PTH 7x/w: TbAr: 68.47\%, Tb.Wi: 14.93 mcm; sham + PTH 7x/w: TbAr: $71.81 \%$, Tb.Wi: $14.70 \mathrm{mcm}$ ) significantly higher than in ORX animals (Tb.Ar: $47.79 \%$, Tb.Wi: $11.23 \mathrm{mcm}$ ) (Table 1) (Fig. 1). 

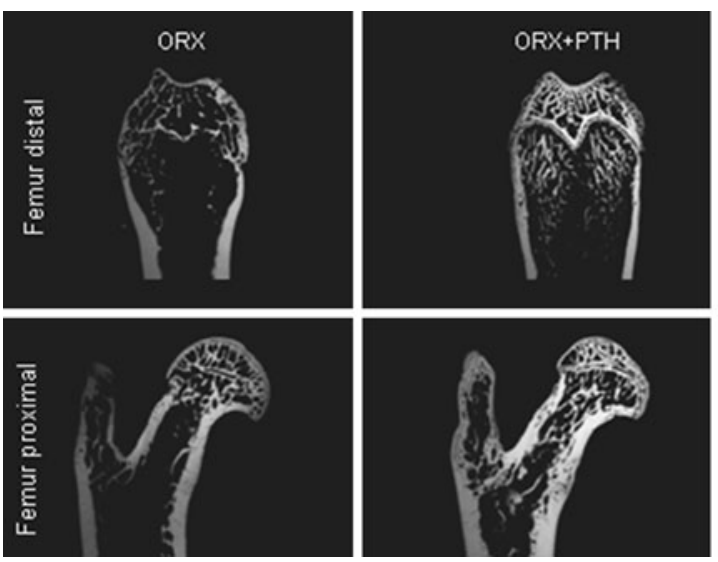

Fig. 1 The figure demonstrates the changes in trabecular structure of distal (upper row) and proximal (lower row) femur of rats with and without treatment of parathyroid hormone (PTH) for 5 weeks. The
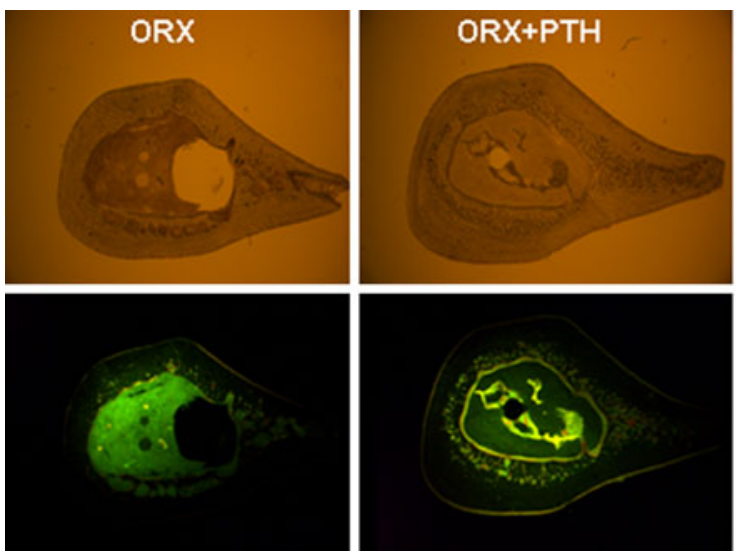

Fig. 2 The figure presents the influence of orchiectomy after 12 weeks and the effect of parathyroid application after 5 weeks. As demonstrated above ("Results"), the decrease in marrow diameter (Ma.Dm) of the cross-sections of proximal rat femur seems to be the mean cause for

Concerning the changes in the cortical surface of prox. femur, the results of B.Dm/Ma.Dm ratio were in all groups significantly higher than in ORX animals (B.Dm/ Ma.Dm $=1.648)$. After PTH treatment, the animals reached in $\mathrm{ORX}+\mathrm{PTH} 7 \mathrm{x} / \mathrm{w}(\mathrm{B} . \mathrm{Dm} / \mathrm{Ma} . \mathrm{Dm}=1.952)$ group the level of sham animals (B.Dm/Ma.Dm = 1.786) (Table 1) (Fig. 2).

The fluorescence microscopy could qualitatively show that after ORX there was only a very small apposition of fluorescent agents. All animals showed after PTH therapy $(\mathrm{ORX}+\mathrm{PTH} 7 \mathrm{x} / \mathrm{w}$ and sham $+\mathrm{PTH} 7 \mathrm{x} / \mathrm{w})$ a clearly higher uptake of fluorescent agents on the endosteal side of proximal femur. In contrast, the influence of ORX and PTH treatment thereafter remained at the periosteal side only minimal (Fig. 2).

Results of the breaking test

The mean level of maximum load $\left(\mathrm{F}_{\max }\right)$ in ORX rats was 158.7 N. With $202.00 \mathrm{~N}$, the mean level of $\mathrm{F}_{\max }$ in
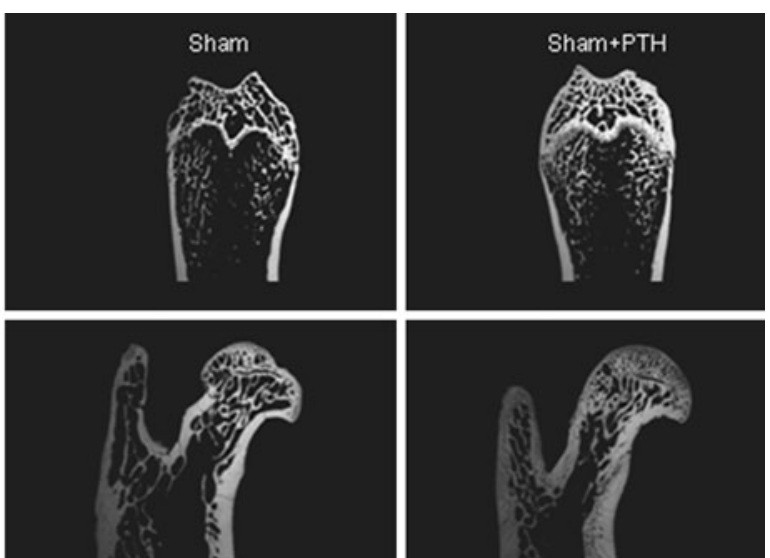

influence of orchiectomy (ORX) on the named areas can clearly be seen in ORX animals. The decrease in trabecular mass and architecture could be prevented after PTH therapy
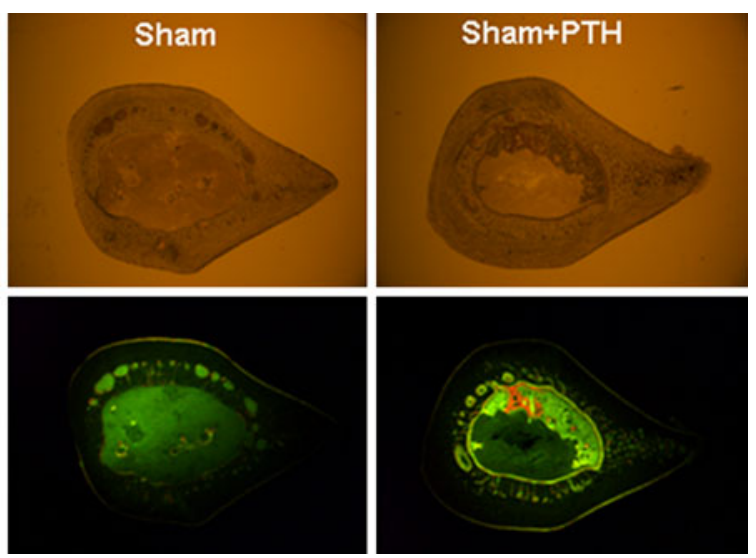

higher B.Dm/Ma.Dm-results in both PTH-treated groups (upper row). This means that the endosteal activity and the increase in bone formation are mainly localized at the endosteal side of the cortical surface. The immunofluorescence microscopy (lower row) confirmed this fact

ORX + PTH $7 x / w$ group was clearly higher in comparison with the ORX group; however, the results, were not statistically significant. In contrast, both the untreated and PTHtreated sham groups (sham $\mathrm{F}_{\max }=212.8 \mathrm{~N}$; sham $+\mathrm{PTH}$ $7 \mathrm{x} / \mathrm{w} \mathrm{F}_{\max }=226.2 \mathrm{~N}$ ) showed significantly higher maximum load compared to untreated ORX animals.

Concerning stiffness, the results were in all groups significantly higher than ORX rats (stiffness $=215.1 \mathrm{~N} / \mathrm{mm}$ ). The best results reached both sham groups (sham stiffness = $325.1 \mathrm{~N} / \mathrm{mm}$; sham + PTH 7x/w stiffness $=322.6 \mathrm{~N} / \mathrm{mm}$ ) (Table 1).

\section{Discussion}

Osteoporosis in men has gained more importance in the last years [1,3]. Although the concept of physiological low testosterone level in elderly men, hormone ablation for 
therapy of advanced prostate carcinoma and treatment of benign prostate hyperplasia by $5 \alpha$-reductase inhibitors, as factors increasing osteoporosis are controversial, facing men with manifest osteoporosis is rising in medical practice $[2,7]$.

The main problem of the reduced bone mineral density is the bone fracture, consecutive chronic skeletal pains, and further disabilities. For osteoporosis in men, there are only a few limited therapy options like bisphosphonate treatment $[1,14]$. In prostate hyperplasia or carcinoma after hormone ablation therapy, the treatment of the hypogonadisminduced osteoporosis is more complicated, because the hormone replacement therapy in such conditions is contraproductive or contraindicated. [7].

The continuous substitution of PTH, as known for example in primary hyperparathyroidism, leads to an increase in bone resorption and formation, but the first component (bone resorption) is here stronger activated than the second (bone formation) $[10,15]$. This imbalance at least, leads to a decrease in bone mineral density. In the last decade, the antiosteoporotic effect of PTH is being more attractive. This goal can be achieved only by an intermittent application of the hormone [16]. The osteoanabolic effect of PTH is already established for treatment of severe postmenopausal osteoporosis in women $[11,17]$.

Parathyroid hormone seems also to be an attractive alternative for treatment of hypogonadism-induced osteoporosis in men [16].

The osteoanabolic effect of PTH after intermittent application can also be seen in bone metastasis of cancers like prostate cancer [18]. It is well possible, that after PTH substitution not only the healthy bone cells (osteoblasts) but also the pathologic cancer metastasis cells in bone can be activated [19].

This fact maybe limits the use of PTH in such cases [18]. Here is the pre-therapeutic staging und evaluation of bone metastasis must be performed. In our opinion, in cases of the absence of bone metastasis, therapy with PTH can be an interesting option.

One of the most important aspects in the therapy of osteoporosis in both men and women is the different intensity of effect of antiosteoporotic drugs on different skeletal sites [10]. For example, it is known that the alendronate (bisphosphonate) seems to be more effective and can better prevent the vertebral body fractures compared to other skeletal sites like proximal femur or proximal tibia $[10,20]$. For this reason, it is very important and necessary to investigate the effect of PTH on different skeletal sites.

One of the most common fracture types in osteoporotic men is the fracture of trochanteric region of femur [21]. In our study, we investigated the short-term effects of parathyroid hormone (PTH) on strength, micro-architecture, and mineral density of trochanteric region of orchiectomized rat. The main changes in the trabecular architecture were due to the increase in trabecular width. In addition, the increase in B.Dm/Ma.Dm ratio after PTH application indicates after separate measuring of B.Dm and Ma.Dm in the proximal femur that PTH mainly activates the endosteal formation of cortex. The periosteal side of the cortical surface remained nearly unaffected. This property was found, in our work, due to a qualitative comparison of fluorescence apposition bands in the cross-sections of proximal femur of rats.

At the end of the study, we observed only a minimally weight gain in ORX rats in comparison with the sham groups (PTH treated and untreated), although many studies in female rats showed a clearly increase in weight after ovariectomy (OVX) [10]. Orchiectomy and ovariectomy seem to affect the fat turn over differently. The exact mechanism of the weight changes in the different male rats after ORX is not exactly cleared.

\section{Conclusion}

In our study, the parathyroid hormone (PTH) was able to treat the hypogonadism-induced bone loss of trochanteric region of rat femur. After therapy with $\mathrm{PTH}$, we observed an increase in bone strength, trabecular micro-architecture, and mineral content in rat femur. Our results show that PTH seems to be a possible treatment option for hypogonadism-induced osteoporosis in men, especially in diseases, where testosterone replacement therapy is contraindicated. Further studies, however, are necessary to prove the efficacy and safety of PTH for treatment of hypogonadisminduced osteoporosis in men, especially after hormone ablation therapy of malignant tumors like prostate cancer.

Conflict of interest The authors have no conflict of interest.

Open Access This article is distributed under the terms of the Creative Commons Attribution Noncommercial License which permits any noncommercial use, distribution, and reproduction in any medium, provided the original author(s) and source are credited.

\section{References}

1. Rocchietti March M, Pisani D, Aliberti G (2009) Male osteoporosis. Minerva Endocrinol 34:325-332

2. Guggenbuhl P (2009) Osteoporosis in males and females: is there really a difference? Joint Bone Spine 76:595-601

3. Kamel HK (2005) Male osteoporosis: new trends in diagnosis and therapy. Drugs Aging 22:741-748

4. Van Tongeren LS, Duncan GG, Kendler DL, Pai H (2009) Implementation of osteoporosis screening guidelines in prostate cancer patients on androgen ablation. J Clin Densitom 12:287-291

5. Maricic M (2010) Intravenous zoledronic acid: what are the indications for male osteoporosis? Curr Osteoporos Rep 8:4-9 
6. Chlebowski RT, Tagawa T (2009) Early breast and prostate cancer and clinical outcomes (fracture). Oncology (Williston Park) 23:16-20

7. Gomella LG (2009) Effective testosterone suppression for prostate cancer: is there a best castration therapy? Rev Urol 11:52-60

8. Partridge NC, Li X, Qin L (2006) Understanding parathyroid hormone action. Ann N Y Acad Sci 1068:187-193

9. Devogelaer JP, Boutsen Y, Manicourt DH (2010) Biologicals in osteoporosis: teriparatide and parathyroid hormone in women and men. Curr Osteoporos Rep 8:154-161

10. Tezval M, Stuermer EK, Sehmisch S, Rack T, Stary A, Stebener M, Konietschke F, Stuermer KM (2010) Improvement of trochanteric bone quality in an osteoporosis model after short-term treatment with parathyroid hormone: a new mechanical test for trochanteric region of rat femur. Osteoporos Int 21:251-261

11. Matsumoto $T$, Shiraki M, Hagino $H$, Iinuma $H$, Nakamura $T$ (2006) Daily nasal spray of hPTH(1-34) for 3 months increases bone mass in osteoporotic subjects: a pilot study. Osteoporos Int 17:1532-1538

12. Ishihara A, Sasaki T, Debari K, Furuya R, Kawawa T, Ramamurthy NS, Golub LM (1999) Effects of ovariectomy on bone morphology in maxillae of mature rats. J Electron Microsc (Tokyo) 48:465-469

13. Parfitt AM, Drezner MK, Glorieux FH, Kanis JA, Malluche H, Meunier PJ, Ott SM, Recker RR (1987) Bone histomorphometry: standardization of nomenclature, symbols, and units. Report of the ASBMR Histomorphometry Nomenclature Committee. J Bone Miner Res 2:595-610

14. Moro-Alvarez MJ, Cabrera JA (2010) Osteoporosis in men. Rev Clin Esp 210:342-349
15. Eriksen EF (2002) Primary hyperparathyroidism: lessons from bone histomorphometry. J Bone Miner Res 17(Suppl 2):N95-N97

16. Gabet Y, Kohavi D, Muller R, Chorev M, Bab I (2005) Intermittently administered parathyroid hormone $1-34$ reverses bone loss and structural impairment in orchiectomized adult rats. Osteoporos Int 16:1436-1443

17. Neer RM, Arnaud CD, Zanchetta JR, Prince R, Gaich GA, Reginster JY, Hodsman AB, Eriksen EF, Ish-Shalom S, Genant HK et al (2001) Effect of parathyroid hormone (1-34) on fractures and bone mineral density in postmenopausal women with osteoporosis. N Engl J Med 344:1434-1441

18. Quirosa Flores S, Varsavsky M, Valle Diaz De La Guardia F, Mijan Ortiz JL, Munoz Torres M, Raya Alvarez E, Zuluaga Gomez A (2010) Secondary hyperparathyroidism in advanced prostate cancer. Endocrinol Nutr 57:100-104

19. Gomes RR Jr, Buttke P, Paul EM, Sikes RA (2009) Osteosclerotic prostate cancer metastasis to murine bone are enhanced with increased bone formation. Clin Exp Metastasis 26:641-651

20. Kaji H, Hisa I, Inoue Y, Naito J, Sugimoto T, Kasuga M (2009) Analysis of factors affecting increase in bone mineral density at lumbar spine by bisphosphonate treatment in postmenopausal osteoporosis. J Bone Miner Metab 27:76-82

21. Woratanarat P, Kijkunastian C, Wajanavisit W, Suppaphol S, Woratanarat T, Rajatanavin R, Boonyaratavej N, Suriyawongpaisal P (2009) A comparative study of risk factors of femoral neck and intertrochanteric fracture in Thai men. J Med Assoc Thai 92(Suppl 6):S165-S171 